\title{
Aging, the Great Moderation and Business-Cycle Volatility in a Life-Cycle Model
}

\author{
Burkhard Heer $^{a, b}$, Stefan Rohrbacher ${ }^{a}$ and Christian Scharrer $^{a}$
}

a University of Augsburg, Department of Economics, Universitatsstrasse 16, 86159 Augsburg, Germany, burkhard.heer@wiwi.uni-augsburg.de, stefan.rohrbacher@wiwi.uni-augsburg.de, christian.scharrer@wiwi.uni-augsburg.de

${ }^{b}$ CESifo, Munich, Germany

JEL classification: J11, E32, C68

Key Words: Business Cycles, Overlapping Generations, Demographics

\begin{abstract}
:
According to empirical studies, the life cycle of labor supply volatility exhibits a Ushaped pattern. This may lead to the conclusion that demographic change induces a drop in output volatility. We present an overlapping generations model that replicates the empirically observed pattern and study the impact of demographic transition on output volatility. We find that the change in age-composition itself has only a marginal influence on output volatility as the mitigating effect of lower labor supply volatility is compensated by higher labor supply. Instead, the driving force behind the Great Moderation in our model is the downward shift of the age-specific labor supply volatility curve.
\end{abstract}

We would like to thank Johann Scharler (University of Innsbruck) for his extensive discussions with us, and for his helpful comments. All remaining errors are ours. 


\section{Introduction}

Nowadays, many industrialized countries face a demographic challenge due to an aging society. Birth rates decline, the probability of survival increases, and thus the proportion of society made up by the elderly gradually increases. In view of this situation, Jaimovich and Siu (2009) provide empirical evidence in a panel of the G7 countries that a demographic transition is closely linked to the volatility of cyclical output. Their results are supported in works by Lugauer (2012a) and Lugauer and Redmond (2012) which point out that age distribution constitutes an important explanatory factor in business cycle analysis. The driving forces behind these observations can be outlined as follows:

On the one hand, higher life expectancy and declining birth rates shift the composition of the labor force away from the young and into prime age groups. Since the cyclical volatility of hours worked depends on age and follows a U-shaped pattern (cf. Clark and Summers (1981), Ríos-Rull (1996), Gomme et al. (2005) and Jaimovich and Siu (2009)), this demographic transition increases the number of older workers with a lower volatility of labor supply. This development leads to a drop in the cyclical volatility of aggregate output. In our paper we label this as the pure demographic effect.

On the other hand, an additional development becomes visible if we divide Jaimovich and Siu's entire dataset with respect to the US labor supply profile by age into two subsamples; before (1963-1984) and during (1985-2005) the Great Moderation. Across all cohorts, the labor supply volatilities by age shifted downwards and the average annual hours worked per person shifted upwards. We call this the shift effect. To the best of our knowledge, this effect has been widely disregarded within the literature so far.

Figure 1.1 summarizes the findings mentioned above. The upper graphs display the evolution of birthrates and survival probabilities in the US. ${ }^{1}$ Evidently, birth rates per

\footnotetext{
${ }^{1}$ The corresponding data is taken from the United Nations (2002) and Mini Historical Statistics, US Census Bureau.
} 
Figure 1.1: Demographic Characteristics
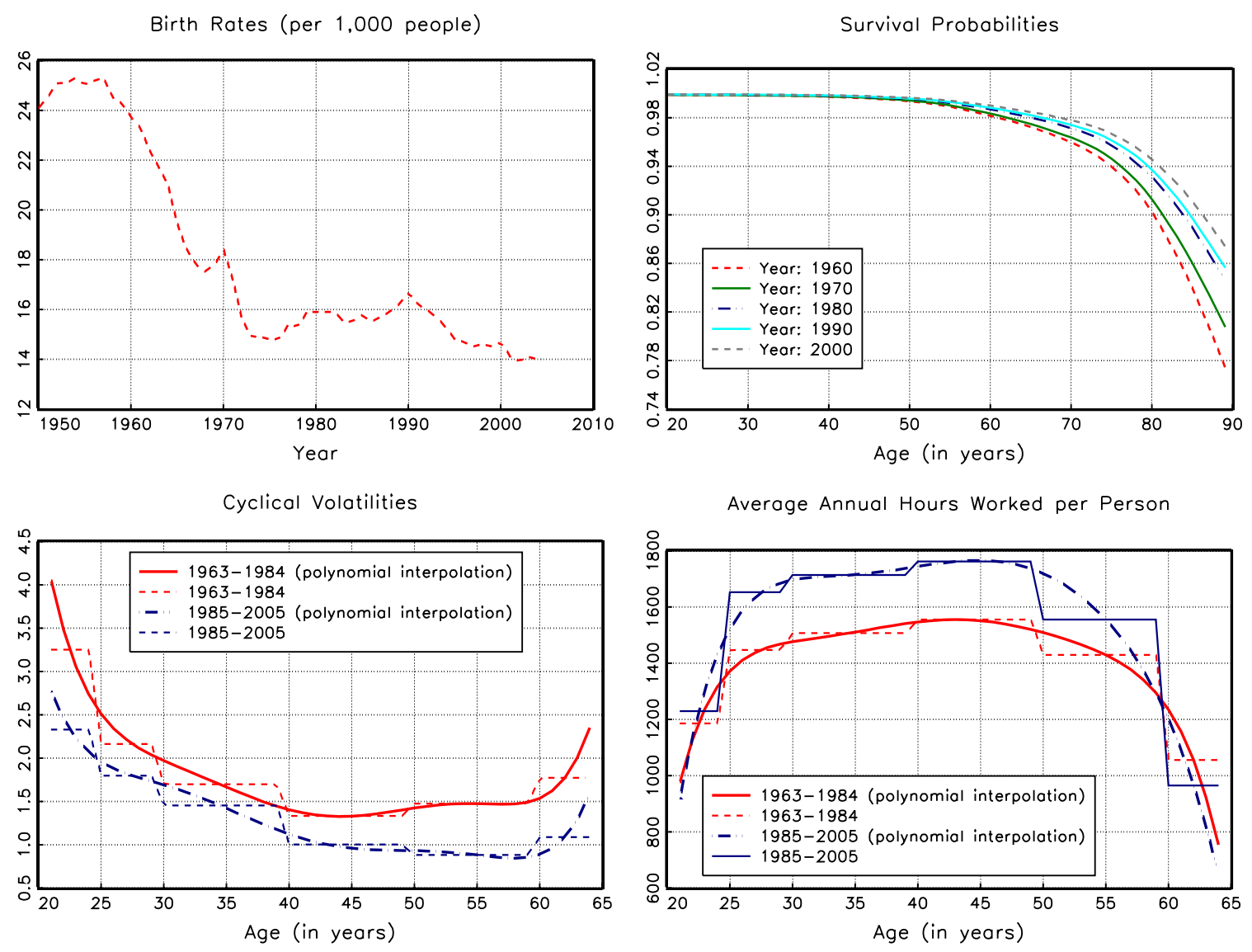

1,000 people dropped from 24 to 14 between 1960 and 2000. In a similar vein, survival probabilities increased during this period, e.g. the survival probability of an 80-year old rose from $90 \%$ to $95 \%$. The lower graphs display the cyclical volatility of hours by age and the average annual hours worked per person for the samples from 1963-1984 and from 1985-2005. ${ }^{2}$ As in Jaimovich and Siu, the term cyclical volatility refers to the business cycle component of volatility of hours worked by age. ${ }^{3}$ While the cyclical volatility of labor decreased by 14-43\% depending on age, the hours worked increased

\footnotetext{
${ }^{2}$ These graphs are based on the dataset by Jaimovich and Siu (2009).

${ }^{3}$ We use a Hodrick-Prescott filter with a smoothing parameter of 100, regress the detrended labor supply of each age group on current and lagged detrended output and detrended aggregate hours, and calculate the standard deviations of the filtered series. The results are reported in the Appendix of this paper.
} 
for those aged 22-58.

In sum, the Great Moderation was accompanied by a pure demographic effect and a shift effect of both labor supply and labor supply volatilities. In order to study how much each effect contributes to the decline in aggregate output volatility we investigate two questions: 1. What would have been the output volatility if the labor volatility had remained on the level it was at before the Great Moderation? In this setting, output volatility is exposed solely to pure demographic effects. 2. How do our results differ if we also allow a downward shift of the cyclical volatility curve and an upward shift of labor supply?

We study these questions in a dynamic stochastic overlapping generations (OLG) model. In contrast to standard real business cycle models with infinitely-lived agents, the OLG framework allows us to take into account the interplay between demographic variables and cohort specific decisions over the life cycle with respect to labor supply and wealth accumulation. In addition, we use the preferences proposed by Greenwood, Hercowitz and Huffman (1988) (GHH) in order to replicate the empirical profiles of labor supply by age and cyclical volatilities in our model. ${ }^{4}$

As our main result, we show that the pure demographic effect plays a marginal role in explaining the empirically observed drop in output volatility. The hump shaped pattern of labor supply during the life cycle (see Figure 1.1) and the relative increase in the mass of older cohorts attenuate the decline in output volatility caused by more individuals with a lower cyclical volatility of labor supply. In contrast, a downward shift of labor supply volatilities plays a crucial role in explaining the decrease in output volatility.

Our work is related to other studies that analyze the impact of aging on business cycle volatility with overlapping generation models and productivity shocks. Ríos-Rull (1996) compares aggregate fluctuations between models with infinitely-lived agents

\footnotetext{
${ }^{4}$ In particular, our preferences feature constant Frisch elasticities. Such preferences are studied extensively by Trabandt und Uhlig (2011). In their general equilibrium model, the magnitude of the Frisch elasticity is most relevant for the estimation of the Laffer curve in the US and EU-14.
} 
and life cycle models, whereas Gomme et al. (2005) focus on the impact of aging on the business cycle fluctuations in hours worked. However, neither study analyzes demographic transition and its ability to explain the Great Moderation. In this vein, Lugauer (2012b) introduces matching frictions in the labor market in order to explain how demographic transition causes the drop in output volatility. However, his analysis focuses entirely on the labor market and, contrary to our study, excludes individual life cycle decisions regarding consumption and the accumulation of wealth. In order to explain the more volatile labor supply of the young over the business cycle, Jaimovich, Pruitt and Siu (2013) introduce capital-experience complementarity in production. Older workers are more experienced and are complementary to capital, while younger workers are not. As opposed to our model, Jamovich et al. distinguish only between young and old workers and hence ignore labor force composition effects that result from changes in birth and death rates.

Our paper is structured as follows. Section 2 describes and explains the benchmark model. In Section 3 we conduct a calibration exercise with respect to the pure demographic and the shift effect. In Section 4, we summarize the main findings of the paper. We analyze the behavior of individuals (4.1), aggregate variables (4.2) and business cycle volatility (4.3) separately. The results of the sensitivity analysis with respect to a pay-as-you-go-system and age-specific productivity profiles are provided in the Appendix.

\section{A 70-period Overlapping Generations Model with Aggre- gate Uncertainty and Accidental Bequests}

In the following, we describe a simple overlapping generations model that is able to map demographic changes. The model is built upon Ríos-Rull (1996) and distinguishes between a household and a production sector. 


\subsection{Demographics}

Every year, a new cohort at age $s=1$ (equivalent to a real life age of 21) enters the economy. Households live a maximum of 70 years corresponding to a real life-time age of 90 . Households survive with age-specific probability $\phi_{s}$ from period age $s$ to $s+1$. Put differently, the parameter $\left(1-\phi_{s}\right)$ denotes the probability of dying at the end of age $s$. Household survival probabilities are illustrated in the top right graph of Fig. 1.1. In addition, population grows at rate $g_{n}$. The number of living agents $L_{t}(s)$ at age $s$ in period $t$ evolves according to the following formula:

$$
L_{t}(s+1)=\frac{\phi_{s}}{1+g_{n}} L_{t}(s)
$$

\subsection{Households}

In the first 44 periods, the households are working; in the last 26 periods, they are retired. Households maximize their expected lifetime utility at age $s=1$ in period $t$ with respect to consumption $c_{t}^{s}$ and labor supply $n_{t}^{s}$ :

$$
E_{t} \sum_{s=1}^{70} \beta^{s-1}\left(\prod_{j=1}^{s-1} \phi_{j}\right) \frac{1}{1-\eta}\left\{\left(c_{t+s-1}^{s}-\gamma_{0}^{s}\left(n_{t+s-1}^{s}\right)^{\gamma^{s}}\right)^{1-\eta}-1\right\} .
$$

Instantaneous utility is a function of both consumption $c_{t}^{s}$ and labor $n_{t}^{s}$ with GHH preferences. This kind of utility function has a property by which it eliminates wealth effects regarding the choice of optimal labor supply. ${ }^{5}$ Since labor supply decisions do not depend on consumption, the empirical patterns of labor supply and corresponding labor supply elasticities can be perfectly matched. The age-dependent constant $\gamma^{s}$ controls the Frisch elasticity of labor supply which is given by $1 /\left(1-\gamma^{s}\right)$. The parameter $\gamma_{0}^{s}$ pins down the steady state labor supply profiles across cohorts.

Households accumulate savings in the form of capital. Let $k_{t}^{s}$ denote the capital stock of the $s$-year old in period $t$. The initial endowment with capital is zero, $k_{t}^{1}=0$. The

\footnotetext{
${ }^{5}$ We have experimented with other preferences, e.g. Cobb-Douglas preferences in consumption and leisure, but have found that GHH preferences allow for the most accurate matching of age-specific labor supply behavior.
} 
working agent of age $s$ receives income from labor, capital, and lump-sum transfers from the government $t r_{t}$. He faces the following budget constraint in period $t$ :

$$
k_{t+1}^{s+1}=\left(1+r_{t}-\delta\right) k_{t}^{s}+w_{t} n_{t}^{s}+t r_{t}-c_{t}^{s}, \quad s=1, \ldots, 44,
$$

where $w_{t}$ and $r_{t}$ denote the real wage rate and the interest rate, respectively. Capital depreciates at the rate $\delta$. The budget constraint of the retired worker is given by ${ }^{6}$

$$
k_{t+1}^{s+1}=\left(1+r_{t}-\delta\right) k_{t}^{s}+t r_{t}-c_{t}^{s}, \quad s=45, \ldots, 70,
$$

with $k_{t}^{71}=0$ and $n_{t}^{45}=n_{t}^{46}=\ldots=n_{t}^{70}=0$.

\subsection{Production}

Production $Y_{t}$ is characterized by a constant returns to scale production function and is assumed to be Cobb-Douglas:

$$
Y_{t}=Z_{t} N_{t}^{1-\alpha} K_{t}^{\alpha}
$$

where $N_{t}$ and $K_{t}$ denote aggregate labor and capital. The technology level $Z_{t}$ is subject to stochastic shocks in that $\ln Z_{t}$ follows an $\operatorname{AR}(1)$ process:

$$
\ln Z_{t}=\rho \ln Z_{t-1}+\epsilon_{t}
$$

where $\epsilon_{t}$ is i.i.d., $\epsilon_{t} \sim N\left(0, \sigma^{2}\right)$.

\subsection{Equilibrium}

In a factor market equilibrium, it must hold that all factors are rewarded with their marginal product:

$$
\begin{aligned}
& w_{t}=(1-\alpha) Z_{t} N_{t}^{-\alpha} K_{t}^{\alpha}, \\
& r_{t}=\alpha Z_{t} N_{t}^{1-\alpha} K_{t}^{\alpha-1} .
\end{aligned}
$$

${ }^{6}$ In the Appendix A.1.3, we show that our results are insensitive to the introduction of pensions and age-specific productivities. 
Furthermore, individual and aggregate behavior must be consistent:

$$
\begin{aligned}
N_{t} & =\sum_{s=1}^{44} L_{t}(s) n_{t}^{s} \\
K_{t} & =\sum_{s=1}^{70} \frac{L_{t}(s)}{\phi_{s-1}} k_{t}^{s}, \quad \text { where } \phi_{0}=1 \\
C_{t} & =\sum_{s=1}^{70} L_{t}(s) c_{t}^{s}
\end{aligned}
$$

and the goods market clears:

$$
Z_{t} N_{t}^{1-\alpha} K_{t}^{\alpha}=C_{t}+I_{t}
$$

where $I_{t}=K_{t+1}-(1-\delta) K_{t}$. In addition, all accidental bequests are confiscated by the government and transferred as lump-sums to the households implying

$$
t r_{t}=\sum_{s=1}^{70} \frac{\left(1-\phi_{s-1}\right)}{\phi_{s-1}} \frac{L_{t}(s)}{L_{t}}\left[\left(1+r_{t}-\delta\right) k_{t}^{s}\right]
$$

where the number of all living agents in period $t$ is given by $L_{t}=\sum_{s=1}^{70} L_{t}(s)$.

\section{Calibration}

We calibrate the model on an annual basis and compute the deterministic steady state using the methods described in Chapters 9 and 10 in Heer and Maussner (2009). ${ }^{7}$ Furthermore, we also have to conduct time series simulations concerning the calibration of labor supply decisions. A detailed explanation of the aforementioned procedure is provided in the Appendix of this paper. With regard to the demographic characteristics we distinguish between three cases:

Case 1: This is our benchmark case which describes the sample from 1963-1984. We calibrate the age-dependent labor supply $\gamma_{0}^{s}$ and labor supply elasticities $\gamma^{s}$ in order

\footnotetext{
${ }^{7}$ In order to compute the dynamics of the model, we also use a code for the generalized Schur decomposition that is provided by Giordani and Söderlind (2004).
} 
to reproduce the interpolated empirical profiles of average labor supply and cyclical volatility of hours worked so that they fit the solid red lines in the lower graphs of Figure 1.1. The population growth rate $g_{n}$ is set equal to 0.024 and describes the average growth rate from 1950 to $1964 .^{8}$ Moreover, the survival probabilities of a household $\phi_{s}$ are given by the average survival probabilities between 1963 and 1984 .

Case 2: Here, we use the same values for $\gamma_{0}^{s}$ and $\gamma^{s}$ as in Case 1. However, the average population growth rate and survival probabilities stem from the sample from 1985 to 2005. Thus, this thought experiment allows us to measure the pure demographic effect by ruling out the shift effect.

Case 3: In this case, we calibrate all parameters with respect to the sample from 1985-2005 and measure the overall effect. By comparing it with Case 2, this enables us to measure the fall in the aggregate output volatility caused by a downward shift of cyclical volatilities and an upward shift of labor supply.

The remaining parameters are standard in the RBC/DSGE literature and have been chosen as follows: $\beta=0.96, \eta=1.0$ and $\alpha=0.30$. We follow Ríos-Rull (1996) and set the parameter $\delta=0.037$ to match a capital-output ratio of 2.45 in our benchmark case. The parameters of the $\operatorname{AR}(1)$ for the technology are set equal to $\rho=0.814$ and $\sigma=0.0142$. These parameters correspond to annual frequencies by a quarterly $\mathrm{AR}(1)$ process for the Solow residual with parameters 0.95 and 0.00763 , which are the parameters in Prescott (1986). The non-stochastic steady states are characterized by a constant technology level, $Z_{t}=Z=1$. Furthermore, all individual variables and aggregate variables expressed in per capita terms must be constant, too. Therefore, in order to express the equilibrium only in terms of stationary variables, we have to divide aggregate quantities by the number of all living agents $L_{t}$ in period $t$ and define new variables:

$$
\tilde{K}_{t} \equiv \frac{K_{t}}{L_{t}}=\sum_{s=1}^{70} \frac{\psi_{s}}{\phi_{s-1}} k_{t}^{s}, \quad \tilde{Y}_{t} \equiv \frac{Y_{t}}{L_{t}}, \quad \tilde{I}_{t} \equiv \frac{I_{t}}{L_{t}} \quad \text { and } \quad \tilde{N}_{t} \equiv \frac{N_{t}}{L_{t}}=\sum_{s=1}^{44} \psi_{s} n_{t}^{s} .
$$

\footnotetext{
${ }^{8}$ Note that, since a household enters the economy at age 21 , we have to apply a lag of 20 years to the birth rates.
} 
The term $\psi_{s}$ denotes the corresponding population weights which are given by

$$
\psi_{s}=\frac{\prod_{i=1}^{s} \phi_{i-1} /\left(1+n_{g}\right)^{s-1}}{\sum_{s=1}^{70}\left\{\prod_{i=1}^{s} \phi_{i-1} /\left(1+n_{g}\right)^{s-1}\right\}} .
$$

In the following, we express stationary variables without a time index. For example, $k^{s}$ and $\tilde{K}$ denote the non-stochastic steady state capital stock of an individual at age $s$ and the non-stochastic steady state aggregate capital stock, respectively.

\section{Results}

In this section, we simulate our model for the periods 1963-84 and 1985-2005 separately and study the impacts of the pure demographic effect and the shift effect on the model economy described above. Firstly, we focus on changes in the individual behavior of households that are caused by the aforementioned effects. Secondly, we analyze the behavior of aggregate variables and show that the demographic effect only has an impact on capital, and not on labor, while the shift effect impacts upon both capital and labor significantly. Thirdly, we consider the volatilities of aggregate variables as measured by their standard deviation (of the filtered series) and demonstrate again that the shift effect of the labor supply is the main source for the change in the volatility of output between 1963-84 and 1985-2005.

\subsection{Individual Behavior}

The behavior of individual age-specific variables is depicted in Figure 4.1 for each Case 1-3. The red solid line depicts Case 1 (1963-84), the green dotted line describes Case 2 (the pure demographic effect in period 1985-2005), and the blue broken line exhibits Case 3 (with both the demographic and the shift effect in 1985-2005). The first row presents the profiles of consumption, labor supply and wealth accumulation during the life cycle. The second row displays the population weights $\psi_{s}$, the weighted labor supply $\psi_{s} n^{s}$ and the weighted capital stock $\frac{\psi_{s}}{\phi_{s-1}} k^{s}$ of each cohort. The last row 
illustrates the cyclical volatilities and the corresponding labor supply elasticities. The ordinate denotes the age in years.

Figure 4.1: Stationary Individual Life-Cycle Profiles

Consumption

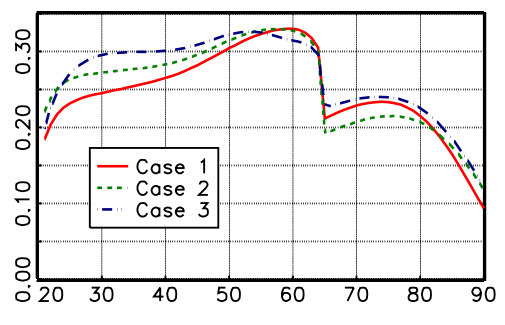

Population Weights (in \%)

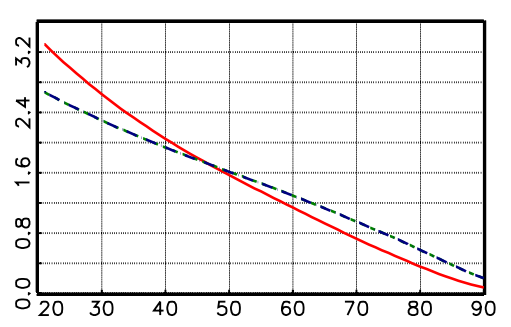

Labor Supply Elasticities

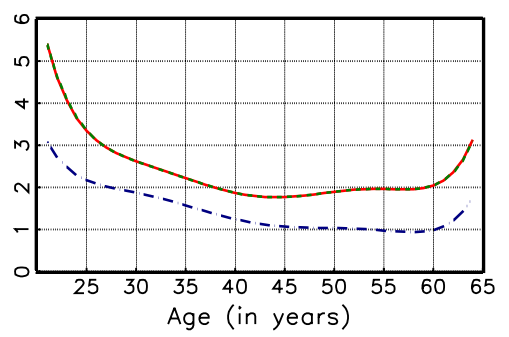

Labor Supply

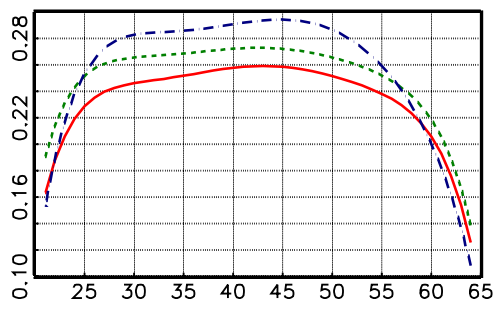

Weighted Labor Supply

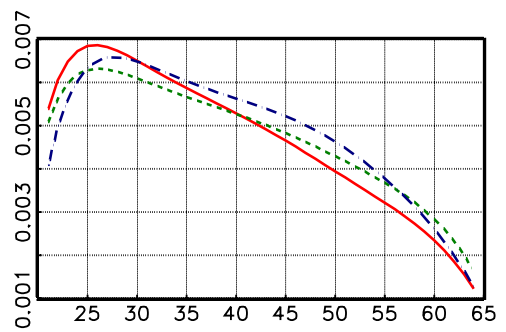

Labor Volatilities by Age

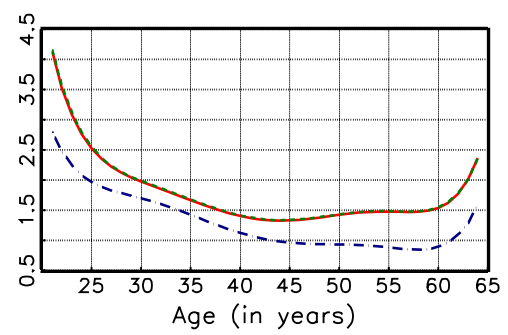

Capital

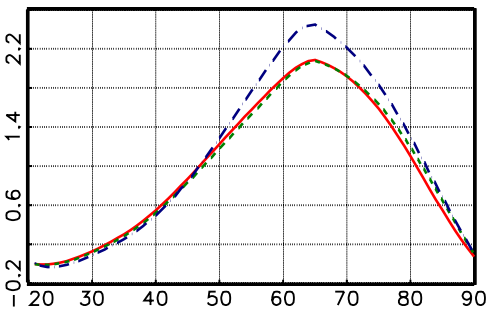

Weighted Capital

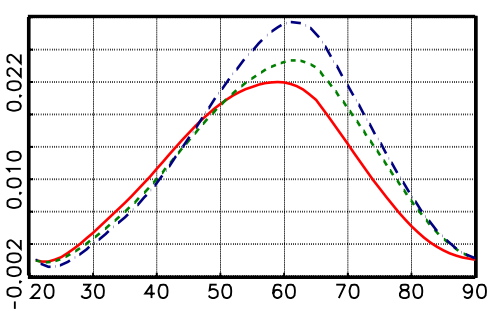

The consumption profiles in the upper left graph are hump-shaped and contain a kink after retirement which can be explained by the non-separable utility function and the mandatory increase in leisure after retirement. The labor supply and cyclical volatilities in Cases 1 and 3 are equal to the empirical profiles shown in the bottom row of Figure 1.1. This is a direct result of our calibration strategy. Furthermore, the profiles of capital accumulation are also hump-shaped and reach a peak at age 64 , shortly before a household enters retirement. Comparing our benchmark case with Case 2 , we can see that a lower fertility rate and a higher life expectancy lead to an increase in labor supply across all cohorts in Case 2. Thus, the pure demographic effect plays a crucial role in explaining the empirically observed increase in the average annual hours 
worked by age from the period 1963-1984 to 1985-2005. The accumulation of individual wealth in Case 2 remains almost unaffected because of the higher consumption of younger age groups. In Case 3, households up to an age of 56 years also spend a larger portion of their income on consumption. However, the accumulation of wealth of older cohorts increases strongly compared to Case 1 and Case 2.

The graph at the bottom left corner displays the Frisch labor elasticities by age group which measure the percentage change in hours worked due to a percentage change in real wages. On the one hand, these elasticities are larger than those usually predicted by microeconomic estimates which typically fall in the range 0 to 1 (see, e.g., Keane (2011) and Kimball and Shapiro (2008) for a survey). However, on the other hand, Keane and Rogerson (2012) argue that larger Frisch labor elasticities in macro-based models are consistent with those in the micro labor supply literature. In contrast to micro Frisch elasticities associated with fluctuations of hours of employed workers, macro Frisch elasticities also include workers entering and leaving the labor market. To put it another way, these elasticities are related to changes in the hours worked along both the intensive and extensive margin. Taking these effects into account, Peterman (2012) estimates macro Frisch elasticities for the US economy between 2.9 and 3.1. Since we also intend to incorporate movements on both margins, the larger values of our elasticities - e.g., in the range of 1 to 3 for agents aged 25-60 - are a direct result of our calibration strategy in terms of a perfect matching of empirical cyclical volatilities of labor supply by age.

\subsection{Aggregate Economy}

Table 4.1 summarizes the values of the aggregate variables in our model for Case 13. The demographic effect increases the aggregate capital $\tilde{K}$ from 0.744 (Case 1 ) to 0.826 (Case 2). Even though individual wealth at all ages is hardly affected, aggregate capital increases due to the composition effect. The first panel in the second row of Figure 4.1 reveals that the pure demographic effect decreases the number of workers younger than 47 years and increases the number of older people in the population. The 
direct impact on the demographic composition of the population leads to a moderate decrease in weighted capital of workers $\frac{\psi_{s}}{\phi_{s-1}} k^{s}$ who are younger than 47 years. However, the accumulated wealth of older cohorts increases sharply, as can be seen from the last panel of the second row in Figure 4.1.

Aggregate labor $\tilde{N}=0.207$ remains nearly constant and the composition effect of the demographic change on $\tilde{N}$ is almost completely compensated for by the humpshaped pattern of labor supply and, especially, by the aforementioned increase in labor supply over time across all cohorts. As shown in the second figure of the second row, the decline in weighted labor supply $\psi_{s} n^{s}$ among workers aged between 21 and 40 is slightly dominated by an increase in the weighted labor supply of older workers.

In Case 3, we also take into account the empirical observations on the behavior of the labor supply and its cyclical volatility during 1985-2005. As a consequence of the increase in labor supply, consumption and wealth accumulation increase during the life cycle. Equally, aggregate capital and average labor supply rise relative to those in Cases 1 and 2. For example, the shift effect causes the aggregate capital $\tilde{K}$ to increase from 0.826 to 0.912 .

In both Cases 2 and 3, the capital stock $\tilde{K}$ rises more than the labor supply $\tilde{N}$. As a consequence, the capital-output ratio per capita increases. Similarly, the net return on capital decreases from $8.540 \%$ (Case 1) to $7.740 \%$ (Case 2) and $7.199 \%$ (Case 3), ${ }^{9}$ while real wages increase due to both the pure demographic effect and the shift effect. Finally, the investment-output ratio per capita decreases from 0.150 in Case 1 to 0.139 in Case 2, while the drop from Case 1 to 3 is smaller (0.146).

\footnotetext{
${ }^{9}$ The percentage point decline in the interest rate between the years 1963 and 2005 predicted by our model is almost exactly the same as the one predicted by Krueger and Ludwig (2007) for the change of the interest rate between the years 2005 and 2040. In particular, they compute a decline in the interest rate from $7.5 \%$ in the year 2005 to $6.6 \%$ in the year 2040. Contrary to our model, however, they analyze an open-economy model of the US economy.
} 
Table 4.1

Aggregate Variables

\begin{tabular}{ccccccc}
\hline \hline & $\tilde{K} / \tilde{Y}$ & $\tilde{K}$ & $\tilde{I} / \tilde{Y}$ & $\tilde{N}$ & $r-\delta$ & $w$ \\
\hline Case 1 & 2.451 & 0.744 & 0.150 & 0.207 & $8.540 \%$ & 1.028 \\
Case 2 & 2.622 & 0.826 & 0.139 & 0.208 & $7.740 \%$ & 1.058 \\
Case 3 & 2.753 & 0.912 & 0.146 & 0.215 & $7.199 \%$ & 1.080 \\
\hline
\end{tabular}

Notes: Case 1 depicts the period 1963-84, Case 2 factors in the pure demographic effect in the period 1985-2005, and Case 3 considers both the demographic and the shift effect in the period 1985-2005.

\subsection{Business Cycle Volatility}

Table 4.2 displays the standard deviations of $\log$ transformed output $\tilde{Y}$, labor supply $\tilde{N}$, investment $\tilde{I}$, capital $\tilde{K}$, consumption $\tilde{C}$, and wage $w$ for each case ${ }^{10} .{ }^{11}$ The contribution of a pure demographic effect on the standard deviations of aggregate output, labor supply and wages is rather moderate. For example, the standard deviation of output decreases by only 0.013 from Case 1 to Case 2 (compare the first entries in rows 1 and 2 of Table 4.2). The decline in the volatilities of capital and consumption is a little more pronounced. Only investment volatility rises noticeably. The aforementioned changes, however, are much more distinct in Case 3, after taking the shift effect into account. In particular, the volatility of aggregate output per capita declines by 0.355, amounting to $13.5 \%$, with respect to Case 1 . Accordingly, the shift effect plays a crucial role in explaining the drop of output volatility in the Great Moderation in

\footnotetext{
${ }^{10}$ We use a Hodrick-Prescott filter with a default smoothing parameter of 100 for annual data and simulate 10,000 time series with a length of 1,000 periods in our model. All variables are expressed in real terms and the second moments are averages over all simulations.

${ }^{11}$ Evidently, we are able to produce standard characteristics of business cycle volatilities, e.g. the volatilities of investment and consumption relative to that of output. In accordance with our model results, e.g. Cooley and Prescott (1995, p. 30) find that, empirically, investment is about 4.79 times as volatile as output, while consumption is less volatile than output ( 0.74 times).
} 
our model.

Table 4.2

Standard Deviations of Aggregate Variables

\begin{tabular}{ccccccc}
\hline \hline & $\tilde{Y}$ & $\tilde{N}$ & $\tilde{I}$ & $\tilde{K}$ & $\tilde{C}$ & $w$ \\
\hline Case 1 & 2.640 & 1.875 & 7.743 & 0.794 & 1.800 & 0.750 \\
Case 2 & 2.627 & 1.858 & 8.399 & 0.749 & 1.756 & 0.755 \\
Case 3 & 2.285 & 1.372 & 7.777 & 0.696 & 1.408 & 0.903 \\
& & & & & & \\
\hline
\end{tabular}

Notes: Time series with a length of 1,000 periods were HP-filtered with weight 100. The second moments are averages over 10,000 simulations.

The impulse response functions of output, labor supply, consumption, investment, and capital in Figure 4.2 support our findings and are able to provide an economic intuition. We analyze a percentage increase in output productivity from the stationary level and compare the effects for every case. We assume that the economy is hit by a productivity shock in period $1 .^{12}$ In accordance with our results on the cyclical volatility of the model variables presented in Table 4.2, the impulse responses vary little between Cases 1 and 2. As suggested by the changes in volatilities, the amplitude of the impulse responses in Case 2 is marginally lower for all variables but investment. The pure demographic effect has a weak impact on the dynamic impulse response of output because the response of labor and capital remains almost unaffected. In contrast, the reaction of labor and capital to a productivity shock is reduced significantly if we take the shift effect (Case 3) into account. Hence, the response of output is also less pronounced.

The economic intuition behind the minor difference between Cases 1 and 2 can be

\footnotetext{
${ }^{12}$ In general, the impulse responses of aggregate variables are very similar to those predicted by standard models with infinitely-lived households. The productivity shock leads to an immediate increase in output, labor supply, consumption and investment. Capital grows steadily and reaches its largest magnitude after 8 to 10 years with respect to each case. Thereafter, the increase abates. Investment expenditures show the strongest reaction.
} 
explained by decomposing the aggregate responses of labor supply and capital into individual responses across cohorts:

$$
\hat{N}_{t}=\sum_{s=1}^{44} \frac{n^{s} \psi_{s}}{N} \hat{n}_{t}^{s} \text { and } \hat{K}_{t}=\sum_{s=1}^{70} \frac{k^{s} \psi_{s}}{K \phi_{s-1}} \hat{k}_{t}^{s},
$$

where a hat over a variable denotes the log-deviation from its corresponding steady state value. ${ }^{13}$ Accordingly, the demographic composition and the changes in the life cycle profiles regarding labor supply and wealth accumulation directly influence the aggregate impulse responses. For illustrative purposes, the lower graphs in Figure 4.2 plot the weighted individual impulse responses of labor supply $\frac{n^{s} \psi_{s}}{N} \hat{n}_{t}^{s}$ and the future capital stock $\frac{k^{s} \psi_{s}}{K \phi_{s-1}} \hat{k}_{t+1}^{s}$ in period 1 across ages in a cross-sectional perspective.

In Case 2, the upward shift of labor supply depicted in Figure 4.1, the (constant) pattern of labor supply elasticities over the life cycle and the demographic composition effect cancel each other out. In comparison to Case 1, the decline of weighted impulse responses in the labor supply of cohorts younger than 40 years is compensated for by a higher weighted labor supply response in older workers. There are more individuals with a lower elasticity of labor supply in an aging population because of the U-shaped pattern of labor supply elasticities across cohorts. This channel attenuates the response of aggregate labor supply. However, the interaction between the increase in labor supply across the cohorts and the changing population weights $\frac{n^{s} \psi_{s}}{N}$ works in the opposite direction. In sum, the overall impact on the aggregate labor supply is only marginal. Furthermore, the weighted contribution of capital of older cohorts increases whereas the impact of younger individuals on the aggregate stock of capital decreases. The overall effect on aggregate capital and, therefore, output is also negligible with respect to the impulse response of output.

In contrast, the downward shift of both labor supply elasticities and the corresponding volatilities of labor supply across workers dominates the strong upward shift of labor

\footnotetext{
${ }^{13}$ Please note that we drop the tildes " " in the remainder of our paper in order to avoid any notational inconvenience. Hence, all following aggregate variables like $K_{t}$ or $N_{t}$ have to be interpreted in per capita terms.
} 
Figure 4.2: Impulse Responses in the OLG model
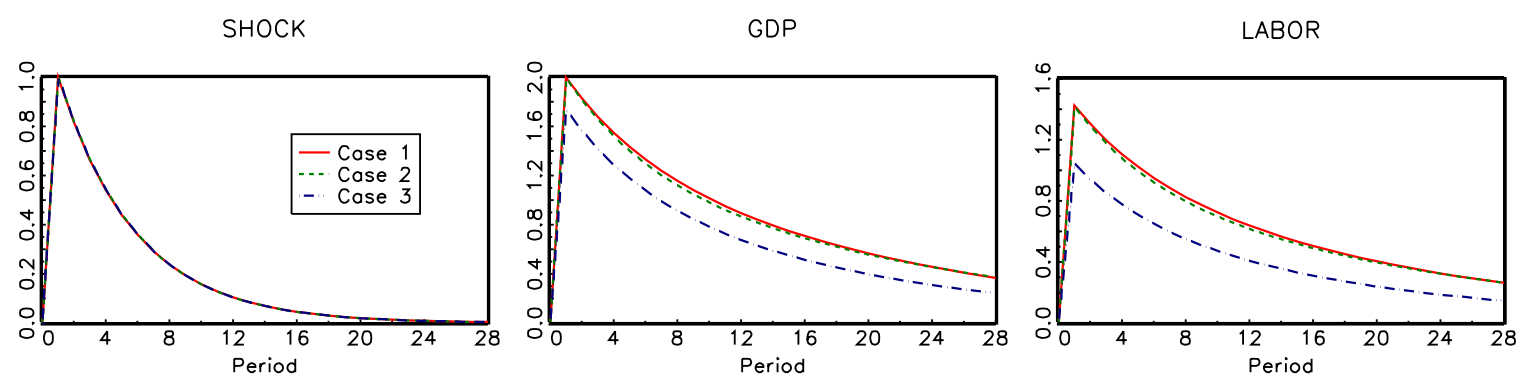

CONSUMPTION
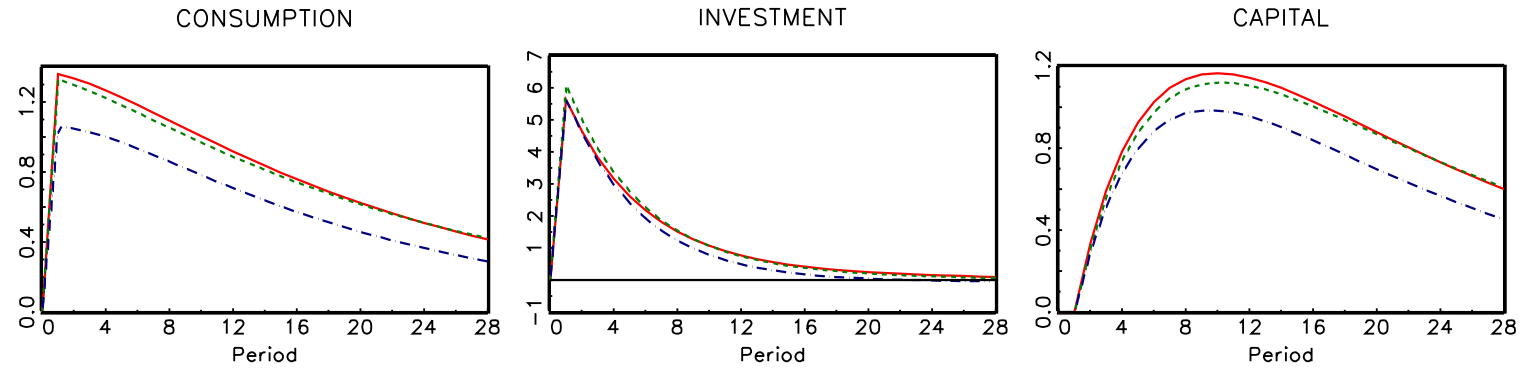

Weighted Labor by Age in $t=1$

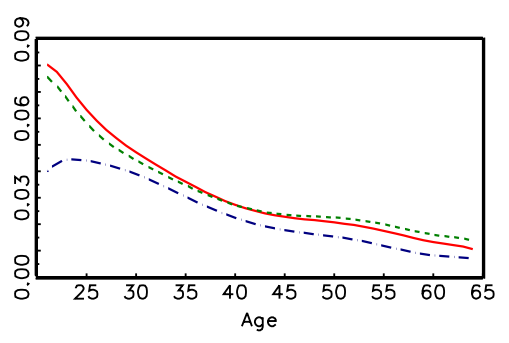

Weighted Capital by Age in $\mathrm{t}=2$

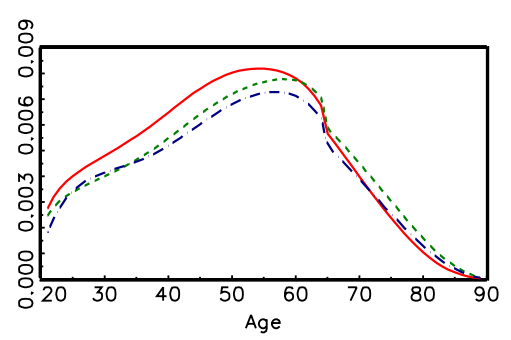

supply and changing population weights in Case 3. Hence, the impulse response of the aggregate labor supply is also smaller. Moreover, the lower response of labor frees up less resources which can be used for consumption and investment. Therefore, the impulse responses of capital are also reduced.

\section{Conclusion}

Declining birth rates and increasing life expectancies shift the composition of the labor force away from the young and into prime-age groups. This development has an attenuating effect on the volatility of output and aggregate labor supply since the volatility of hours worked is an empirically observed U-shaped function of age. However, during the Great Moderation, this pure demographic effect was also accompanied by a 
downward shift of cyclical volatilities of labor supply across all age groups.

We present an overlapping generations model that replicates the empirically observed age-specific volatilities of labor supply and explicitly takes changes in the age-composition into account in order to study the impacts of both effects on aggregate output volatility before and during the Great Moderation. An increase in labor supply across cohorts and changes in age composition caused by an aging population compensate for the pure demographic effect as long as a demographic transition is not also exposed to a pronounced downward shift of volatilities of labor supply across cohorts. We find that in this case the volatility of output remains almost unaffected and decreases only marginally. In contrast, shifts of age-specific volatilities of labor supply play a crucial role in determining the strength of output volatility and are able to explain a reduction of the output volatility by $13 \%$. According to our results, the decline in output volatility during the Great Moderation was primarily driven by lower labor supply elasticities across all age groups. 


\section{References}

Blundell, R., and T. Macurdy, 1999, Labor supply: A review of alternative approaches, in: O. Ashenfelter and D. Card (eds.), Handbook of Labor Economics, Vol. 3, Chapter 27, North Holland, Amsterdam, 1559-1695.

Clark, K., and L. Summers, 1981, Demographic Differences in Cyclical Employment Variation, Journal of Human Resources 16(1), 61-79.

Cooley, T. F., and E. C. Prescott, Frontiers of Business Cycle Research, in: T. F. Cooley (ed.), Frontiers of Business Cycle Research, Princeton University Press, Princeton, NJ, 1-38.

Giordani, P., and P. Söderlind, 2004, Solution of macromodels with Hansen-Sargent robust policies: some extensions, Journal of Economic Dynamics and Control 28(12), 2367-2397.

Gomme, P., R. Rogerson, P. Rupert and R. Wright, 2005, The Business Cycle and the Life Cycle, in: M. Gertler and K. Rogoff (eds.), National Bureau of Economic Research Macroeconomics Annual 19, MIT Press, Cambridge, MA, 415-46.

Greenwood, J., Z. Hercovitz, and G. W. Huffman, 1988, Investment, Capacity Utilization, and the Real Business Cycle, American Economic Review 78(3), 402-417.

Hansen, G. D., 1993, The Cyclical and Secular Behaviour of the Labor Input: Comparing Efficiency Units and Hours Worked, Journal of Applied Econometrics 8(1), 71-80.

Heer, B., and A. Maussner, 2009, Dynamic General Equilibrium Models: Computational Methods and Applications, 2nd ed., Springer-Verlag, Berlin.

Jaimovich, N., S. Pruitt, and H. E. Siu, 2013, The Demand for Youth: Explaining Age Differences in the Volatility of Hours, American Economic Review, forthcoming. 
Jaimovich, N., and H. E. Siu, 2009, The Young, the Old, and the Restless: Demographics and Business Cycle Volatility, American Economic Review 99(3),804826.

Keane, M., 2011, Labor Supply and Taxes: A Survey, Journal of Economic Literature 49(4), 961-1075.

Keane, M., and R. Rogerson, 2012, Micro and Macro Labor Supply Elasticities: A Reassessment of Conventional Wisdom, Journal of Economic Literature 50(2), 464-476.

Kimball, M. S., and M. D. Shapiro, 2008, Labor Supply: Are the Income and Substitution Effects Both Large or Both Small?, NBER Working Papers 14208, National Bureau of Economic Research, Inc.

Krueger, D., and A. Ludwig, 2007, On the Consequences of Demographic Change for Rates of Returns to Capital, and the Distribution of Wealth and Welfare, Journal of Monetary Economics 54, 49-87.

Lugauer, S., 2012a, Estimating the Effect of the Age Distribution on Cyclical Output Volatility Across the United States, The Review of Economics and Statistics 94(4), 896-902.

Lugauer, S., 2012b, Demographic Change and the Great Moderation in an Overlapping Generations Model with Matching Frictions, Macroeconomic Dynamics 16(5), 706-731.

Lugauer, S., and M. Redmond, 2012, The Age Distribution and Business Cycle Volatility: International Evidence, Economics Letters 117(3), 694-696.

Peterman, W., 2012, Reconciling Micro and Macro Estimates of the Frisch Labor Supply Elasticity, Finance and Economics Discussion Series 2012-75, Board of Governors of the Federal Reserve System (U.S.).

Prescott, E. C., 1986, Theory ahead of business cycle measurement, Carnegie Rochester Series on Public Policy 25, 11-44. 
Ríos-Rull, J.-V., 1996, Life-Cycle Economies and Aggregate Fluctuations, Review of Economic Studies 63(3), 465-489.

Trabandt, M., and H. Uhlig, 2011, The Laffer curve revisited, Journal of Monetary Economics 58, 305-327.

United Nations, 2002, World Population Prospects: The 2002 Revision, United Nations Population Division, United Nations, New York. 


\section{A.1 Appendix}

\section{A.1.1 Log-Linearization of the Benchmark Model in Section 3}

In order to solve the model numerically, we log-linearize the equations characterizing the economy around the non-stochastic steady state. These equations, in particular, consist of the first-order conditions of the households and the firm, the budget constraint of the households, and the government budget constraint.

The first-order conditions of the households for $s=1, \ldots, 70$ in period $t$ are given by:

$$
\begin{aligned}
w_{t} \lambda_{t}^{s} & =\left(c_{t}^{s}-\gamma_{0}^{s}\left(n_{t}^{s}\right)^{\gamma^{s}}\right)^{-\eta} \gamma_{0}^{s} \gamma^{s}\left(n_{t}^{s}\right)^{\gamma^{s}-1} \\
\lambda_{t}^{s} & =-\eta \frac{c^{s}}{\left(c-\gamma_{0}^{s}\left(n^{s}\right)^{\gamma^{s}}\right)} \\
\frac{1}{\beta} & =E_{t}\left\{\frac{\lambda_{t+1}^{s+1}}{\lambda_{t}^{s}} \phi_{s}\left[1+r_{t+1}\right]\right\}
\end{aligned}
$$

Log-linearization of (A.1.1)-(A.1.3) around the non-stochastic steady state results in:

$$
\begin{aligned}
& \hat{n}_{t}^{s}=\frac{1}{\gamma^{s}-1} \hat{w}_{t}, s=1, \ldots, 44, \\
& \hat{\lambda}_{t}^{s}=-\eta \frac{c^{s}}{\zeta^{s}} \hat{c}_{t}^{s}+\eta \gamma^{s} \gamma_{0}^{s} \frac{1}{\zeta^{s}}\left(n^{s}\right)^{\gamma^{s}} \hat{n}_{t}^{s}, s=1, \ldots, 44, \\
& \hat{\lambda}_{t}^{s}=E_{t} \hat{\lambda}_{t+1}^{s+1}+\frac{r}{1+r-\delta} E_{t} \hat{r}_{t+1}, \quad s=1 \ldots, 69,
\end{aligned}
$$

where $\zeta^{s}=c^{s}-\gamma_{0}^{s} n^{\gamma^{s}}$. Furthermore, we need to log-linearize the working household's budget constraint (2.1) around the steady state for the one-year old with $k^{1} \equiv 0$ :

$$
k^{2} \hat{k}_{t+1}^{2}=w n^{1} \hat{w}_{t}+w n^{1} \hat{n}_{t}^{1}+\operatorname{tr} \hat{t r}_{t}-c^{1} \hat{c}_{t}^{1}
$$

and for $s=2, \ldots, 44$ :

$$
k^{s+1} \hat{k}_{t+1}^{s+1}=(1+r-\delta) k^{s} \hat{k}_{t}^{s}+r k^{s} \hat{r}_{t}+w n^{s} \hat{w}_{t}+w n^{s} \hat{n}_{t}^{s}+\operatorname{tr} \hat{t} r_{t}-c^{s} \hat{c}_{t}^{s}
$$

Log-linearization of the retired agent's budget constraint (2.2) around the non-stochastic steady state results in:

$$
k^{s+1} \hat{k}_{t+1}^{s+1}=(1+r-\delta) k^{s} \hat{k}_{t}^{s}+r k^{s} \hat{r}_{t}+\operatorname{tr} \hat{t} r_{t}-c^{s} \hat{c}_{t}^{s}, \quad s=45, \ldots, 70
$$


Finally, consumption at age $s=70$ is given by:

$$
c^{70} \hat{c}_{t}^{70}=(1+r-\delta) k^{70} \hat{k}_{t}^{70}+r k^{70} \hat{r}_{t}+t r \hat{t} r_{t}
$$

Therefore, we have 70 controls $c_{t}^{s}(s=1, \ldots, 70), 44$ controls $n_{t}^{s}(s=1, \ldots, 44), 70$ costates $\lambda_{t}^{s}(s=1, \ldots, 70)$, and 69 predetermined variables $k_{t}^{s}(s=2, \ldots, 70)$. We also have $70+44+70+69=253$ equations. We have three further endogenous variables $w_{t}, r_{t}$, and $t r_{t}$. The wage rate is given by the marginal product of labor:

$$
w_{t}=(1-\alpha) Z_{t} K_{t}^{\alpha} N_{t}^{-\alpha}=(1-\alpha) Z_{t}\left(\sum_{s=1}^{70} \frac{\psi_{s}}{\phi_{s-1}} k_{t}^{s}\right)^{\alpha}\left(\sum_{s=1}^{44} \psi_{s} n_{t}^{s}\right)^{-\alpha}
$$

Log-linearization results in:

$$
\hat{w}_{t}=\hat{Z}_{t}+\alpha \sum_{s=1}^{70} \frac{\psi_{s}}{\phi_{s-1}} \frac{k^{s}}{K} \hat{k}_{t}^{s}-\alpha \sum_{s=1}^{44} \psi_{s} \frac{n^{s}}{N} \hat{n}_{t}^{s} .
$$

Similarly, we derive the percentage deviation of the interest rate, $\hat{r}_{t}$, from its nonstochastic steady state $r=\alpha N^{1-\alpha} K^{\alpha-1}$ :

$$
\hat{r}_{t}=\hat{Z}_{t}-(1-\alpha) \sum_{s=1}^{70} \frac{\psi_{s}}{\phi_{s-1}} \frac{k^{s}}{K} \hat{k}_{t}^{s}+(1-\alpha) \sum_{s=1}^{44} \psi_{s} \frac{n^{s}}{N} \hat{n}_{t}^{s} .
$$

Government transfers $t r_{t}$ are approximated log-linearly as follows:

$$
\hat{t} r_{t}=\sum_{s=1}^{70} \frac{\left(1-\phi_{s-1}\right)}{\phi_{s-1}} \psi_{s-1}\left((1+r-\delta) \frac{k^{s}}{t r} \hat{k}_{t}^{s}+\frac{r k^{s}}{t r} \hat{r}_{t}\right)
$$

Finally, we have the law of motion for the exogenous state variable $Z_{t}$ :

$$
\hat{Z}_{t+1}=\rho \hat{Z}_{t}+\epsilon_{t}
$$

\section{A.1.2 Calibration of Cyclical Volatilities and Labor Supply across Cohorts}

Let $\sigma^{s, c}$ and $n^{s, e}$ denote the cyclical volatility (see also Appendix A.1.4) and the empirical mean of labor supply of a household at age $s$ with respect to one of our two samples from 1963-1984 and 1985-2005. The log-linearized first-order condition (A.1.4) of a cohort with respect to labor supply is given by:

$$
\hat{n}_{t}^{s}=\frac{1}{\gamma^{s}-1} \hat{w}_{t}
$$


Thus, the absolute level of labor supply evolves according to the following equation in our model:

$$
n_{t}^{s}=n^{s}\left(1+\hat{n}_{t}^{s}\right)=n^{s}\left(1+\frac{1}{\gamma^{s}-1} \hat{w}_{t}\right)
$$

After taking logs it must hold that:

$$
\log \left(n_{t}^{s}\right)=\log \left(n^{s}\right)+\log \left(1+\frac{1}{\gamma^{s}-1} \hat{w}_{t}\right) \approx \log \left(n^{s}\right)+\frac{1}{\gamma^{s}-1} \hat{w}_{t} .
$$

The implied standard deviation can be written as:

$$
\sigma\left(\log \left(n^{s}\right)\right)=\frac{1}{\gamma^{s}-1} \sigma(\hat{w})
$$

Replacing $\sigma\left(\log \left(n^{s}\right)\right)$ by its empirical counterpart, $\sigma^{s, c}$, and rearranging yields:

$$
\gamma^{s}=\frac{\sigma(\hat{w})}{\sigma^{s, c}}+1
$$

This condition pins down $\gamma^{s}$. Furthermore, the first-order conditions with respect to consumption and labor supply, (A.1.1) and (A.1.2), imply the labor supply of the s-year-old, $n^{s}$ :

$$
n^{s}=\left(\frac{w}{\gamma_{0}^{s} \gamma^{s}}\right)^{\frac{1}{\gamma^{s}-1}}
$$

This condition determines $\gamma_{0}^{s}$ after replacing $n^{s}$ by $n^{s, e}$.

We start with an initial guess of $\sigma(\hat{w})$ in our time series simulation with a length of 1,000 periods and update our guess until convergence.

\section{A.1.3 Sensitivity Analysis}

In this section we introduce a pay-as-you-go system and age-specific productivities in our benchmark model. We assume additionally that agents receive public pensions $b_{t}$ during retirement irrespective of their employment history. The new budget constraint (2.2) of a retired worker is given by:

$$
k_{t+1}^{s+1}=\left(1+r_{t}-\delta\right) k_{t}^{s}+t r_{t}+b_{t}-c_{t}^{s}, \quad s=45, \ldots, 70
$$


The government collects contributions from workers in order to finance its pension payments to retired agents. Here, we assume that the contribution rate $\tau$ is constant and that labor income depends on a normalized age-specific productivity profile $e_{s}$ which is taken from Hansen (1993). Therefore, the budget constraint of active workers (2.1) is modified as follows:

$$
k_{t+1}^{s+1}=\left(1+r_{t}-\delta\right) k_{t}^{s}+(1-\tau) e_{s} w_{t} n_{t}^{s}+t r_{t}-c_{t}^{s}, \quad s=1, \ldots, 44
$$

Furthermore, the pensions system is balanced in every period t:

$$
\sum_{s=45}^{70} L_{t}(s) b_{t}=\tau w_{t} \sum_{s=1}^{44} L_{t}(s) e_{s} n_{t}^{s} .
$$

We compute the income tax rate for a given steady-state replacement ratio of pensions with respect to net income equal to $40 \%, \zeta=\frac{b}{(1-\tau) w \bar{n}}=40 \%$. The term $\bar{n}$ denotes the average effective labor supply in the economy.

Table A.1.1 summarizes our findings with respect to the volatilities generated by our modified benchmark model. Evidently, the main results of the simpler model still hold in the case of age-specific labor productivities and pensions. In particular, output volatility is hardly affected by the demographic shift (Case 2), but falls significantly for the labor supply volatility shift (Case 3). The magnitude of the fall in output volatility in the modified model is of the same order as in the benchmark model of Section 2, as the standard deviation of output (first entry column in Table A.1.1) falls by $13.1 \%$ (compared to $13.5 \%$ in the model of Section 2). 
Table A.1.1

Standard Deviations of the Modified Benchmark Model

\begin{tabular}{ccccccc}
\hline \hline & $\tilde{Y}$ & $\tilde{N}$ & $\tilde{I}$ & $\tilde{K}$ & $\tilde{C}$ & $w$ \\
\hline Case 1 & 2.582 & 1.789 & 8.355 & 0.853 & 1.733 & 0.779 \\
Case 2 & 2.562 & 1.762 & 9.324 & 0.825 & 1.676 & 0.786 \\
Case 3 & 2.243 & 1.309 & 8.543 & 0.759 & 1.368 & 0.925 \\
& & & & & & \\
\hline
\end{tabular}

Notes: Time series with a length of 1,000 periods were HP-filtered with weight 100. The second moments are averages over 10,000 simulations.

\section{A.1.4 Empirical Volatility of Hours Worked by Age Groups}

Table A.1.2 displays the filtered and cyclical volatilities of annual hours worked in the US economy during the two periods from 1963-1984 and from 1985-2005. The term cyclical volatilities refers to volatilities that are correlated with the business cycle and is computed with the help of the projection of the annual hours worked by age on a constant, current and lagged detrended real output and aggregate hours. Furthermore, we use the Hodrick-Prescott (HP) filter with a smoothing parameter of 100 for detrending. The data source for aggregate variables is the FRED database. 
Table A.1.2

Empirical Volatility of Hours Worked by Age Groups, US

\begin{tabular}{rrrrrrr}
\hline 1963 to 1984: & $20-24$ & $25-29$ & $30-39$ & $40-49$ & $50-59$ & $60-64$ \\
\hline Filtered Volatility & 3.89 & 2.98 & 1.95 & 1.61 & 1.73 & 2.79 \\
Cyclical Volatility & 3.25 & 2.16 & 1.70 & 1.33 & 1.48 & 1.77 \\
$R^{2}$ & 0.70 & 0.61 & 0.81 & 0.69 & 0.74 & 0.54 \\
& & & & & & \\
\hline Filtered Volatility & 2.54 & 1.95 & 1.50 & 1.11 & 0.96 & 1.55 \\
Cyclical Volatility & 2.33 & 1.80 & 1.45 & 1.00 & 0.88 & 1.09 \\
$R^{2}$ & 0.80 & 0.81 & 0.89 & 0.77 & 0.79 & 0.48 \\
\hline
\end{tabular}

